\title{
Canadian Consensus Conference on the Treatment of Gastroesophageal Reflux Disease
}

\author{
IT BECK, J CONNON, S LEMIRE, ABR THOMSON \\ AND OTHER PARTICIPANTS
}

R BOURdages, C CARMichael, N Charland, h Chaun, R Clermont, LR DaCosta, D DAly, WD DauphineE, W Depew, n Diamant, H Haddad, R Hunt, A Johnson, AV Klein, R Keith, T Lay, D Leddin, D MacNaughton, J McHattie, JB Meddings, D Mercer, D PAtel, W PAterson, E ProkipChuk, I ProkopiW, R Reynolds, RH Riddell, R Sherbaniuk, J Sidorov, EA Shaffer, WG ThOMPSON, N WILliams, L WOROBETZ, J Wright

\section{SUMMARY}

This was the first Consensus Conference of the Canadian Association of Gastroenterology (CAG). The subject of gastroesophageal reflux disease (GERD) was selected because of the existence of widespread controversy regarding first the classification, pathophysiology and methods of investigation; and secondly, the approach to the therapy of GERD. In relation to the first area, four issues were discussed: definition of disease severity; methods of investigation; relative importance of acid and motility in the pathogenesis of GERD; and complications. Regarding the approach to therapy, four areas were considered: therapy with lifestyle modification and over-the-counter therapy; approach to initial therapy; maintenance therapy; and medical versus surgical therapy, including treatment of complications. Each section was introduced to the entire group of participants by prepared talks on background information. This was followed hy discussion in small groups of seven to 12 participants each. The small group sessions were then summarized by the session Chairperson, and were presented for further discussion to the entire group of 40 participants. The Chairperson then prepared a written summary of the group discussion.

Agreement was reached in most areas and a suggested decision tree for the management of patients with GERD was developed: the majority of persons with GERD symptoms have mild gastroesophageal reflux disease; most people with GERD do not see a physician, and most do well on self-administered over-the-counter therapy. When the person presents to his/her family physician, the suggested initial treatment for symptomatic GERD should consist of lifestyle modification, over-thecounter therapy and $\mathrm{H}_{2}$-blockers. Prokinetics as initial treatment should be used only under special conditions. Probably about two persons in three will improve on lifestyle modification, over-the-counter therapy and $\mathrm{H}_{2}$-blockers. If the patient with symptoms of GERD does not respond to this initial four to eight weeks of therapy, the physician has to suspect the presence of more serious disease such as erosive esophagitis, esophagitis with complications, or disease other than GERD. Therefore, before starting proton pump inhibitors, endoscopy is indicated. Diagnostic motility studies ( $24 \mathrm{~h} \mathrm{pH}$ and/or motility and Bernstein test) are needed only under special conditions. GERD is a chronic relapsing disease and frequently maintenance therapy is needed, particularly when the patient has had endoscopically-proven erosive esophagitis. Maintenance therapy should be undertaken with the least potent drug that prevents relapse. To date, in severe disease the best data for maintenance therapy would favour the use of a proton pump inhibitor over standard doses of an $\mathrm{H}_{2}$-blocker, but higher doses of $\mathrm{H}_{2}$-blocker therapy may prove to be useful in some patients. Most patients with GERD (even those with complications) can be managed medically, but there are surgical indications to be considered in individual patients. A 'Decision Tree' for the suggested management of patients with GERD was developed to facilitate the clinical approach to this common clinical condition.

The opinions expressed at this conference represent a consensus based on what we know today, and should not be taken as a definitive guide to practice for every patient and under all circumstances. (Pour résumé, voir page 278) 


\section{Conférence canadienne pour un consensus sur le traitement du reflux gastro-oesophagien}

\section{RÉSUMÉ}

Il s'agissait de la première conférence canadienne de l'Association canadienne de gastro-entérologie en vue d'établir un tel consensus. Le thème du reflux gastro-œesophagien a été retenu à cause de l'importante controverse qui subsiste à son endroit, notamment aux chapitres (1) de la classification, de la physiopathologie, des méthodes diagnostiques; et (2) des approches thérapeutiques. La première partie abordait quatre aspects principaux, soit (I) une définition de la gravité de la maladie; (II) les méthodes diagnostiques; (III) l'importance relative de l'acidité et de la motilité dans la pathogenèse du reflux gastrocesophagien; et (IV) les complications. Pour ce qui est des approches face à la thérapie, quatre secteurs ont également fait l'objet de présentations : (1) traitement par modifications du mode de vie et médicaments vendus sans ordonnance; (2) traitement initial; (3) traitement d'entretien; et (4) traitement médical versus chirurgical, y compris traitement des complications. Chaque section a été présentée à tout le groupe des participants sous forme de synthèses qui furent suivies de discussions par petits groupes de sept à 12 personnes. Les séances par petits groupes ont ensuite été résumées par le président de la séance, puis présentées de nouveau au groupe entier de 40 participants. Le président a ensuite soumis un résumé écrit au groupe pour poursuivre la discussion.

Une entente a été conclue dans la plupart des domaines et une formule a été suggérée pour le traitement des patients souffrant de reflux gastro-cesophagien: la majorité des gens qui manifestent des symptômes de reflux gastro-œesophagien présentent la maladie à un degré léger; la plupart ne voient pas le médecin et se contentent de s'auto-administrer un traitement vendu sans ordonnance. Lorsque le patient se présente chez son médecin de famille, le traitement initial suggéré des symptômes de reflux gastro-esophagien doit comprendre des modifications au mode de vie, les médicaments vendus sans ordonnance appropriés et des anti- $\mathrm{H}_{2}$. Les agents prokinétiques en traitement initial ne sont employés que dans des circonstances spéciales. Environ deux personnes sur trois verront probablement leur état s'améliorer grâce à certaines modifications de leur mode de vie, aux médicaments sans ordonnance et aux anti- $\mathrm{H}_{2}$. Si le patient ne répond pas à cette forme de traitement dans les quatre à huit semaines, Le médecin doit soupçonner un problème plus grave, comme l'oesophagite corrosive, l'cesophagite compliquée ou une pathologie autre que le reflux gastro-ossophagien. C'est pourquoi il est recommandé de recourir à une endoscopie avant d'amorcer un traitement aux inhibiteurs de la pompe à protons. Les examens diagnostiques de motilité ( $\mathrm{pH}$ sur $24 \mathrm{~h}$ et/ou test de perfusion acide où de Bernstein) ne sont requis que dans certaines conditions. Le reflux gastro-øesophagien est une maladie chronique récidivante, et il est souvent nécessaire d'administrer un traitement d'entretien, particulièrement si l'endoscopie a révélé des lésions d'œesophagite corrosive. Le traitement d'entretien doit être entrepris avec le médicament efficace le moins puissant apte à prévenir les rechutes. Jusqu'à présent, dans les cas graves, les données le plus favorables en matière de traitement d'entretien appuient le recours aux inhibiteurs de la pompe à protons plutôt qu'aux anti- $\mathrm{H}_{2}$ à doses standard, mais ces derniers peuvent se révéler utiles à doses élevées chez certains patients. La plupart des patients souffrant de reflux gastro-oesophagien (même en présence de complications) peuvent être traités médicalement, mais il y a des indications à la chirurgie dans certains cas précis. La formule mise au point pour la sélection du traitement dans les cas de reflux gastro-cesophagien vise à faciliter l'approche clinique de ce problème courant.

Les opinions exprimées lors de cette conférence représentent le consensus établi sur la base du savoir actuel et ne doivent pas être considérées comme des directives définitives à mettre en pratique chez tous les patients et dans tous les cas.

I: MEDICINE WERE TRULY AN EXACT SCIENCE, CONSENSUS conferences would not be necessary. However, medicine depends not only on science, and much of what we do can best be referred to as the 'art of medicine'. This is because today's medical practice is based on many complex and interrelating factors. Basic observations in physiology, pathology, pathophysiology, pharmacology and other accurate sciences establish facts, on which basis the understanding of disease and treatment are made. The results of most scientific observations can be interpreted in many different ways, and thus controversy may exist on the application of the results of even the most scientifically correct laboratory studies or properly controlled human clinical trials. For example, medical therapy may be based on well controlled double-blind prospective studies. Unfortunately, most of these studies are carried out on relatively small numbers of patients, and in most of these trials there are numerous exclusion criteria (pregnant women; children; persons who use other medications; or patients who are severely ill with other diseases such as diabetes, cardiovascular disease and other similar conditions). Therefore, results of even the best double-blind studies are not necessarily applicable to a wide variety of patients. Because of the small number of patients included in most studies, multiple small trials are sometimes combined in a meta-analysis to provide for the analysis of a larger number of cases. Even though the inclusion criteria of studies combined into the meta-analysis are usually well defined, one cannot help but wonder how bias can be avoided during the selection of trials for inclusion into the analysis.

Other sources of information that may influence a physician in his/her decision to use a certain drug in their practice are the results of single-blind prospective studies, retrospective analysis of a large number of cases, case reports and even occasionally personal experience. All of these findings may be tainted by the opinions and biases of estab. lished authorities in the field, and by the various pressures which may be exerted to clarify interpretation, and by the publication of data collected and distributed by even the most ethical members of the pharmaceutical industry. Perhaps the most important aspect of what we do is based on our own personal observations, which inevitably result from our own biases: don't we all tend to remember our good results, but forget our complications? Thus, with all these factors influencing individual decision-making, it is hard to be totally 'objective'. 
We hope that this and future Canadian Association of Gastroenterology (CAG) Consensus Conferences may reach common conclusions as to the understanding of the pathophysiology of a number of gastrointestinal disorders, and develop a common reasoned and reasonable approach to management of these conditions. We recognize that the practice of medicine is based on both art and science; therefore, consensus is fluid, and may change over time as new knowledge and experience become available.

Why did the CAG decide to hold its first consensus conference on gastroesophageal reflux disease (GERD)? Recently, a number of new concepts have been introduced in relation to the classification, pathophysiology, clinical aspects and therapy of GERD. It was necessary to come to a consensus as to whether the classification of GERD should be based on symptoms, on endoscopic (and/or biopsy) findings, or on the response to therapy. There is controversy regarding the role of acid or of abnormal motility as the primary pathogenetic factor in GERD. In the past, it was understood that clearing of the esophagus from refluxed intragastric material was of major importance. Now we understand that in severe GERD there are motility changes which interfere with acid clearance from the esophagus. Are these changes temporary or do they become irreversible, leading to a permanent deterioration in acid clearance? Many patients with GERD have recurrent symptoms; is maintenance therapy necessary? New methods of investigation have been introduced in the recent past. In addition to the time-honoured methods of barium meal and endoscopy, we can study motility patterns of the esophagus and measure gastroesophageal reflux by intraesophageal $\mathrm{pH}$ recording, and in some centres combine this with $24 \mathrm{~h}$ motility studies. There are numerous esophageal and extra-esophageal complications of GERD, and accordingly it was necessary to discuss the risk of carcinoma in Barrett's esophagus and the frequency of pulmonary and laryngeal complications in patients with GERD. Thus, the items for our consideration and discussion included an evaluation of old and new techniques needed to diagnose GERD. How far should the family physician investigate patients with GERD? When does the patient need to see a gastroenterologist?

With the recent introduction of drugs with major acid suppressing capacity, controversy has arisen as to whether the physician has to treat every GERD patient with profound acid suppression, such as with a proton pump inhibitor. Because of this, we felt that we should try to reach a consensus on the management of patients with (GERD. We discussed what might be the proportion of persons with mild reflux who actually see a physician; of those who do, how many require profound acid inhibitory therapy? Is there evidence that mild GERD can be treated with lifestyle modification alone, or with modest acid inhibition? For the management of those persons who do not respond to lifestyle modification, multiple therapeutic approaches exist. Therefore, it was important to come to a consensus as to what drug should be used for initial therapy. Should the physician start treating the patient with antacids, a prokinetic agent, an $\mathrm{H}_{2}$-receptor antagonist, or with combination therapy? Should one start treatment in every patient with a proton pump inhibitor, or should the physician first assess the patient and then initiate therapy according to each patient's need? The excellent initial therapeutic results with drug therapy, yet the rapid relapse rate after discontinuation of administration of these agents, establishes the fact that GERD is a chronic recurrent illness and that maintenance therapy is necessary in selected patients. Therefore, we needed to come to a consensus as to which patients need maintenance therapy, and with which drugs, who are the patients needing long term profound acid suppression, and what are the known and proven long term effects of nearly complete acid suppression? It was also important to discuss whether a need still exists for surgery in GERD; and it was necessary to consider what the indications for medical and surgical management of complications of GERD should be.

\section{ORGANIZATION PROCESS}

The individuals invited to the Consensus Meeting represented a broad base of Canadian expertise. Three family physicians were selected, and were individuals with an interest in the academic aspects of GERD. Gastroenterologists, a surgeon and a pathologist at teaching hospitals were selected on the basis of their clinical acumen, teaching interests and respected common sense. Subspecialists ('esophagologists') were also invited to provide focus on very specific and detailed issues. There was a broad representation on the basis of age and geographical location across the country. Drs Beck and Thomson organized the meeting and prepared this manuscript, with the valuable input of Drs Suzanne Lemire and Joe Connon, President of the CAG, and Chairperson of the Education Committee of the CAG, respectively. All of the participants had an opportunity to comment on the draft proposal and to offer their suggestions for changes.

An educational grant was obtained from Glaxo Canada, with the money donated to the CAG and administered by Dr Lawrence Worobetz, Treasurer of the CAG. The topics to be covered, the speakers and the discussants were agreed upon by Drs Beck, Connon, Lemire and Thomson. The sponsor had no input and no opportunity to control the selection of participants, the topics to be covered, or the preparation of this report. A suggestion to include international authorities was rejected, since we wished this to be a truly Canadian perspective.

The program was divided into sections (Tables 1,2), and all participants were involved in the presentations and/or workshops. Following a series of state-of-the-art addresses, the members broke off into pre-assigned workshops, in which they undertook to resolve pre-set issues. After the two hour workshop, the Chairperson of each workshop reported their suggestions and recommendations to the entire group. These were then discussed with all members present. Where necessary and appropriate, the consensus recommendations were revised to reflect the view of the entire group of participants. The proceedings were recorded, the transcript of the summaries was distributed to the summarizers, corrected, and 
TABLE 1

Pathophysiology and clinical aspects of gastroesophageal reflux disease

\section{DEFINITION OF DISEASE SEVERITY}

Classic concepts

R Clermont

Could severity of disease be judged by

nonresponsiveness to a moderate

dose of an $\mathrm{H}_{2}$-blocker?

$\begin{array}{ll}\text { Participants } & \text { C Carmichael } \\ & \text { HChaun } \\ & \text { D Daly } \\ & \text { W Dauphinee } \\ & \text { D Patel }\end{array}$

Summarizer/Chairperson

LDaCosta

RELATIVE IMPORTANCE OF MOTILITY AND ACID

Motility

Acid

R Reynolds

Participants

R Hunt

NCharland

TLay

EProkipchuk

N Williams

Summarizer/Chairperson

N Diamant

WHOM TO INVESTIGATE, WHEN, HOW AND BY WHOM COST-EFFECTIVENESS AND VARIOUS METHODS
The family physician's outlook

Investigation by a specialist

Participants

Summarizer/Chairperson

\section{COMPLICATIONS OF GERD}

Esophageal complications

Extra-esophageal complications

Participants

A Johnson

R Bourdages

H Haddad

D Mercer

I Prokopiw

J Sidorov

L Worobetz

J Wright

EShaffer

S Lemire

W Paterson

J Connon

A Klein

D Leddin

D MacNaughton

$\mathrm{J}$ Meddings

R Riddell

Summarizer/Chairperson

J McHattie

returned to the coauthors of this document for proofreading, and incorporation into a preliminary report. This was circulated to all participants, who were provided with an opportunity to comment and to recommend appropriate changes. Then, a final report was submitted to The Canadian Joumal of Gastroenterology. Since the report had already been critically reviewed by 40 persons, it was not submitted to further peer review, but was examined by the Eastern Editor-inChief, Dr CN Williams.

The organizers divided the discussion into two sections, the first dealing mainly with pathophysiology and clinical aspects of GERD, and the second dealing with management of the patient with GERD. The four groups discussed the definition of GERD, its investigation, the relative importance

TABLE 2

Management of the patient with gastroesophageal reflux disease

\section{DO LIFESTYLE MODIFICATIONS (LSM) AND \\ OVER-THE-COUNTER THERAPY (OCT) WORK?}

What is the evidence that LSM and OCT W Paterson work in the therapy of GERD?

What is the prevalence of patients in G Thompson whom LSM and OCT alone would work?

Participants

D Daly

A Johnson

D Patel

I Prokopiw

R Reynolds

N Williams

Summarizer/Chairperson

EProkipchuk

SHOULD INITIAL DRUG THERAPY BE PROKINETICS, $\mathrm{H}_{2}$-RECEPTOR BLOCKERS OR PROTON PUMP INHIBITORS?

Prokinetics

$\mathrm{H}_{2}$-blockers

Proton pump inhibitors

HChaun

Participants

J Wright

L Worobetz

R Bourdages

NCharland

R Clermont

$J$ Meddings

E Shaffer

Summarizer/Chairperson

L DaCosta

\section{MEDICAL MAINTENANCE THERAPY}

When is maintenance therapy indicated $\mathrm{R}$ Hunt and for how long?

When is maintenance with $\mathrm{H}_{2}$-blockers N Diamant and prokinetics indicated?

When is maintenance with proton pump D Leddin inhibitors indicated?

What are the ethical aspects of long term J Sidorov maintenance therapy?

Participants

C Carmichael

W Depew

H Haddad

A Klein

S Lemire

J McHattie

R Sherbaniuk

Summarizer/Chairperson

J Connon

\section{MEDICAL VERSUS SURGICAL THERAPY AND MANAGEMENT OF} COMPLICATIONS

Medical therapy of complications

NWilliams

Indications for surgery and operations

Participants

D Mercer

ELalor

T Lay

D MacNaughton

R Riddell

Summarizer/Chairperson

W Dauphinee

of motility and acid in the production of GERD, and the complications of the disease. In the second section another set of four groups discussed therapy under the headings: treatment with lifestyle modification and over-the-counter therapy; initial therapy (with prokinetics, $\mathrm{H}_{2}$-blockers or 
proton pump inhibitors); maintenance therapy; and treatment of complications. Each group was instructed to concentrate on the specific areas assigned to them.

One of the interesting observations made during the reporting of summaries at the Plenary Session was that these groups were unable to totally focus on their assigned subjects, because many of these topics overlapped. For example, groups dealing with classification of GERD severity could not discuss this topic without correlating the severity of GERD with response to therapy; groups dealing with therapy could not deal with this aspect without discussing it in relation to disease severity, nor could they discuss therapy without taking into consideration the pathophysiological cause of the disease. Therefore, there is considerable overlap in the summaries of the group discussions. Notwithstanding, all groups came to the same final classification and therapeutic approach. These similar conclusions of the different groups working separately indicates an even closer consensus of opinion among Canadian gastroenterologists than does the outcome of the final discussions!

\section{PATHOPHYSIOLOGY AND CLINICAL ASPECTS OF GERD}

\subsection{Definition of disease severity}

The topic of The classic concept was introduced by $\mathrm{R}$ Clermont, while the question 'Could severity of disease be judged by nonresponsiveness to a moderate dose of an $\mathrm{H}_{2}$-receptor blocker?" was introduced by W Depew. The participants in this section included C Carmichael, H Chaun, D Daly, D Dauphinee and D Patel. The session was summarized by $\mathrm{L}$ DaCosta.

Disease severity may be defined on the basis of endoscopic findings, or according to the response to therapy. In accordance with Castell's GERD Iceberg Triangle (Figure 1), the majority of persons with symptoms of GERD probably have only mild disease and do not seek medical care. Sometimes symptoms of GERD are elicited on functional inquiry of patients seen for other reasons. Most of these patients are improved on self-medication, even before they see their physician. They probably have mild disease, but as none of them are investigated, it is not known whether any persons in this group have endoscopic esophagitis. Furthermore, it is not known that if they do have erosive esophagitis, what will happen to them. Will they heal in time, or will they go on to develop Barrett's epithelium and esophageal carcinoma?

Some persons with GERD will present at their family physician's office. Whether they have moderate or severe disease can possibly sometimes be assessed on the basis of their symptoms. Therefore, the Consensus Group spent considerable time to come to an agreement on a symptom classification of GERD severity. Mild GERD was defined as the person having:

- reflux symptoms less than once per month;

- symptoms present for less than six months;

- and pain ('heartburn') intensity in symptoms of the order of 1-4 out of a grading of 10 .

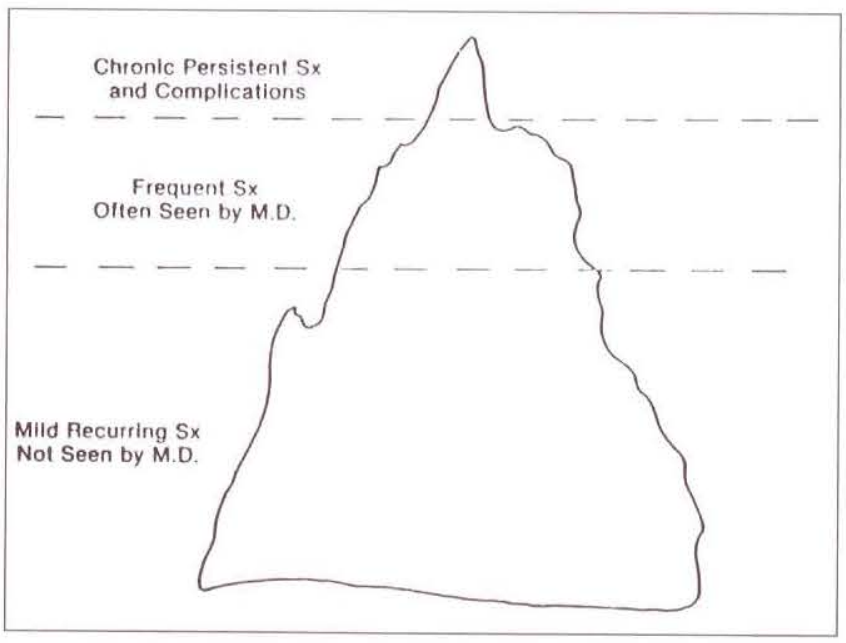

Figure 1) The GERD 'Triangle'. Reprinted with permission from Castell DO. Introduction to pathophysiology of gastroesophageal reflux. In: Castell DO, Wu CW, Ott DJ, eds. Gastroesophageal Reflux Disease: Pathogenesis, Diagnosis, Therapy. New York: Futura, 1985

Severe GERD was defined as the person having:

- daily attacks of reflux pain;

- the symptoms present for longer than six months;

- and pain intensity in the order of 7-10 out of a grading of 10 .

Most of the patients with mild GERD will respond to conventional therapy consisting of lifestyle modification, over-the-counter agents and $\mathrm{H}_{2}$-receptor antagonists. Patients who have 'danger symptoms' such as odynophagia, dysphagia, hemorrhage, or who do not respond to conventional therapy, are likely to have severe disease. There was a $100 \%$ agreement that these patients with suspected severe disease should be referred for endoscopy. The grade of severity of GERD could then be assessed further on the basis of the endoscopic findings. Unfortunately, there is no good GERD severity grading system which has been validated and proven to be reliable and reproducible. The group used a modified Savary grading system: a normal esophagus is one which shows no abnormalities. The presence of erythema was not considered to be abnormal, because of the inherent variability of colour assessment at endoscopy. Grade I esophagitis exhibits friability plus/minus a few erosions. Grade II esophagitis shows discrete erosions, linear erosions and patchy ulcers. Grade III is characterized by circumferential ulcers or deep ulceration. Complications such as Barrett's esophagus and strictures were classified as Grade IV esophagitis.

\subsection{Whom to investigate, when, how and by whom? Cost-effectiveness of various methods}

The topic of the Family physician's outlook was introduced by A Johnson, while the topic of Investigation by a specialist was introduced by $\mathrm{R}$ Bourdages. The participants included $\mathrm{H}$ Haddad, D Mercer, I Prokopiw, J Sidorov, L Worobetz and J Wright. The session was summarized by $E$ Shaffer.

GERD is a clinical syndrome produced by regurgitation of 
acid from the stomach into the esophagus. 'Heartburn', the most common manifestation of GERD, occurs monthly in some 60 million adult Americans (which can be extrapolated to six million Canadians). It is a common entity, although only a small minority of the total GERD population seeks medical attention when symptoms become severe or unremitting. Because the entity is so common and the clinical diagnosis is usually secured by taking a careful history, most persons with symptoms of GERD do not require investigation. Investigations are warranted when complications arise such as atypical chest pain, dysphagia (which can be a 'normal' accompaniment of reflux esophagitis) or gastrointestinal bleeding, when a patient over the age of 40 is experiencing significant symptoms, or when the patient has not undergone previous investigation and has failed on conservative management for four to eight weeks.

The consensus was that the primary investigation should consist of endoscopy, with biopsies of any lesion suspicious of Barrett's epithelium or cancer. A barium swallow is a readily available and useful tool for the family physician. Other studies might be necessary in a selective group of patients. One possibility is $24 \mathrm{~h} \mathrm{pH}$ monitoring, with a $\mathrm{pH}$ electrode placed $5 \mathrm{~cm}$ above the lower esophageal sphincter (LES). This provides a direct method for detecting reflux of gastric contents into the esophagus. $\mathrm{pH}$ monitoring appears to be the most sensitive test currently available to detect reflux, but is limited by availability, expense and problems in accurately positioning the $\mathrm{pH}$ probe. Esophageal manometry documents the pressure events occurring within the body of the esophagus and at the LES, at rest and during swallowing. Manometry can reveal a motility disorder associated with atypical chest pain. Using standard equipment one can perform it at only one point in time, or with more sophisticated apparatus over $24 \mathrm{~h}$. A weak LES may play some role in the pathogenesis of the reflux of gastric contents into the esophagus, but LES dysfunction on a motility tracing is not the sine qua non for GERD. Lastly, the Bernstein test with acid perfusion of the esophagus may reproduce the symptoms of GERD, but does not provide a high degree of sensitivity unless the test is clearly positive.

In the 1990s we have come to recognize that the extent of our health care dollar has a finite limit and that patient management must be predicated on clear-cut definitions of outcome. What we do for our patients must be evaluated in terms of costs, benefits and outcomes. Investigation of symptoms of GERD is expensive, and a good history usually provides the correct diagnosis of GERD in most persons with uncomplicated disease. Primary management of GERD should be by the family physician. The vast majority of patients do not require sophisticated interventions (such as endoscopy, manometry or radiological studies), and conservative therapy (lifestyle modification, over-the-counter therapy, standard doses of $\mathrm{H}_{2}$-blockers) suffices. Mild intermittent symptoms of GERD can be managed by conservative measures which are inexpensive. Some physicians advocate the occasional use of nonabsorbable agents such as antacids, alginic acid (eg, Gaviscon ${ }^{\circledR}$ ) or Sulcrate ${ }^{\circledR}$ (although the aluminum component may pose problems in patients with chronic renal failure). Standard doses of $\mathrm{H}_{2}$-receptor antagonists would be appropriate at this stage. Use of these agents at the recommended doses does carry some expense, but these agents do have a good record of improving the symptoms of GERD.

In summary, the Consensus Group felt that the majority of persons with symptoms of GERD can be appropriately treated by their family physician using conservative management, and that these patients did not normally need referral to a gastroenterologist for a sophisticated investigative procedure.

\subsection{Relative importance of motility and acid}

The topic of Motility was introduced by R Reynolds, and Acid was introduced by R Hunt. The participants included N Charland, T Lay, E Prokipchuk, R Sherbaniuk and N Wil. liams. The session was summarized by N Diamant.

Disordered motility underlies the entry of gastric acid into, and its poor clearance from, the esophagus. The severity of GERD increases as esophageal acid exposure increases. There is a spectrum of symptoms and/or disease (pathology-pathophysiology) in persons with GERD, and this spectrum may be illustrated on the 'GERD 'Triangle' (Figure 1). Using the GERD Triangle as a background, the relative importance of motility and acid may be considered under five headings:

- acid exposure;

- severity of esophagitis;

- motility disorder;

- the sensory pathways; and

- the person's help-seeking illness behaviour.

For each of these categories, there will be a combination of factors that determines which persons come to see doctors, and why they come. Depending on the involvement of any one or all of these factors, the picture at any time from the base of the triangle to the tip may vary considerably. At the base of the GERD triangle, acid exposure and the esophageal mucosa may be normal, but as acid exposure increases, esophagitis becomes more severe and may eventually become complicated.

The motility disorder in GERD is characterized by reduced LES pressure, reduced amplitude of esophageal contractions, and incomplete progression of esophageal contractions. This motility disorder becomes progressively more prominent towards the apex of the GERD triangle. However, at the base of this GERD triangle, gastroesophageal reflux occurs predominantly through transient LES relaxation, which probably represents the dominant mechanism for gastroesophageal reflux in the majority of early cases. Reduced LES pressure and reduced motility of the esophageal body become more prominent in more severe cases, and as the clinical disease progresses.

Sensory mechanisms are important both for the interpretation of symptoms, and as a reflex pathway for some types of abnormal motility (particularly spastic motor disorder) in response to the presence of acid in the esophagus. Sensory 
mechanisms may become depressed with prolonged severe esophagitis, such as is seen in the patient with Barrett's esophagus, and this may contribute further to decreased reflex motor responses. On the other hand, some patients have a highly sensitive esophagus, where even normal amounts of gastroesophageal reflux produce severe symptoms in the absence of pathological mucosal damage. Finally, coupled with the sensory apparatus is the importance which persons place on their symptoms, and how they react to these symptoms. These latter responses may be independent of the severity of gastroesophageal reflux, or the presence of esophagitis or a motor abnormality. Thus, the person's illness behaviour may be more of an issue than the presence of acid, esophagitis or a motor disorder. For example, at the base of the GERD triangle, normal gastroesophageal reflux, in the absence of objective evidence of disease, may sometimes cause severe symptoms and health seeking behaviour, and move such persons to the tip of the triangle. Other patients at the tip of the GERD triangle with severe esophagitis and/or its complications may also have their disease complicated by variations in health-seeking behaviour.

Thus, in the presence of documented esophagitis and with the present knowledge base, treatment is most effective when directed at acid reduction. We need more and better information in a number of areas:

- the importance of lifestyle measures that affect motility and acid, relative to the severity of the disease;

- better understanding of the mechanisms of production of symptoms, particularly as it relates to disorders of motility (such as abnormal spastic contractions), the presence and degree of acid exposure, and sensory mechanisms;

- illness behaviour;

- the effect of treatment on the relationship between symptoms and disease, especially documented esophagitis;

- orher factors that bear on the relationship between symptoms in the presence of disease, especially documented esophagitis;

- who and when to investigate further, and why this investigation should be pursued (outcome and cost-effectiveness); and

- the pathogenesis and etiology of the underlying motor disorder which leads to gastroesophageal reflux, and inhibitory mechanisms (since transient LES relaxation is an inhibitory phenomenon and is prominent in the early stages of GERD).

A number of suggestions arose from the discussions in this group:

- treatment should be directed primarily at acid reduction;

- lifestyle measures, over-the-counter therapy and $\mathrm{H}_{2}$-receptor antagonists are of value in patients with mild disease, but additional therapy may be required as GERD severity increases; and

- referral for investigation should occur on the basis of symptoms; if the symptoms are frequent and persist in the face of therapeutic measures directed to correcting gastroesophageal reflux (including lifestyle modification, over-the-counter therapy, and failure of a four-to six-week course of standard doses of an $\mathrm{H}_{2}$-receptor antagonist), the patient will require an endoscopy, and occasionally other investigations such as manometry.

\subsection{Complications}

The topic of Esophageal complications was introduced by $\mathrm{S}$ Lemire, while the topic of Extra-esophageal complications was introduced by W Paterson. The participants included J Connon, A Klein, D Leddin, D MacNaughton, JB Meddings and RH Riddell. The session was summarized by J McHattie.

It was accepted that patients with erosive esophagitis are best treated with a proton pump inhibitor, such as omeprazole. Because of the high recurrence rate of erosive esophagitis after initial healing, and its potential to progress to fibrosis, stricture and Barrett's epithelium, these patients should remain on maintenance therapy. If severe dysplasia is detected, follow-up endoscopy with multiple biopsies would be recommended at about six-month intervals, and the patient should be treated aggressively for any associated erosive esophagitis. Similarly, esophageal strictures should be treated aggressively. It is uncertain whether these patients with erosive esophagitis should also be followed by routine endoscopy while they remain asymptomatic, since some individuals may continue to have erosive esophagitis and therefore may be at a potential risk of progressing to complications.

Extra-esophageal complications were discussed, and asthma and cough were grouped together. It was felt that if extra-esophageal complications are suspected, patients should be investigated before omeprazole therapy, as the latter may eliminate the opportunity to make a firm diagnosis.

After the reports of the discussions of the first four small groups, the floor was opened for plenary discussion of the four reports. There was discussion regarding the difficulties in defining circular ulceration, the significance of erythema and the classification of endoscopic severity. It was generally agreed that circular ulceration may be difficult to define. For instance, what if $90 \%$ of the mucosa is involved in ulceration, is this to be Grade II or III? Some discussants felt that they can define an erythema, but in general it was felt that there is too much variability in interpretation and that the presence or absence of erythema may also depend on the length of the examination. Some disagreed with the endoscopic classification proposed by the group and preferred the original Savary classification. However, since there is no scientific basis for either, the differences between the two classifications did not raise a major controversy. One of the questions raised at the floor was why not use a proton pump blocker as a useful indicator for failure of medical therapy. Dr DaCosta answered that the group has considered this question and felt that it was reasonable to treat all patients with a potent new drug which is expensive and which is safe in the short term, but its long term effect is not fully known. Fur- 
thermore, once the proton pump inhibitors are started for whatever indication, they may be continued for a prolonged period, particularly when $60 \%$ of the moderately ill patients do not need it. Omeprazole, undoubtedly, is the drug of choice for severe erosive esophagitis and for patients with confirmed GERD who have not responded to standard therapies which include a trial with standard doses of an $\mathrm{H}_{2}$-receptor antagonist. It is clear that a longer duration of acid suppression is needed to alleviate symptoms.

Because many patients with GERD will be correctly diagnosed by history and physical examination, and symptoms will be relieved by antacids or $\mathrm{H}_{2}$-receptor antagonists, only those individuals who fail to respond or have 'danger symptoms' normally need to undergo endoscopic investigation. It was felt that a barium swallow or an upper gastrointestinal series was of very limited value in such individuals; instead, this should only be undertaken in association with an endoscopy in a patient with a suspected obstructing lesion. This approach would greatly diminish the demand for consultations, endoscopy or radiological investigations. Because most patients with simple GERD will do well on four to eight weeks' therapy with over-the-counter agents or $\mathrm{H}_{2}$ receptor antagonists, followed by intermittent and on demand therapy, the cost for the management of this condition would be moderate and potentially diminished from the current cost. Prior to considering placing a patient with severe symptoms on maintenance therapy, however, it would be necessary for the family physician to know that they were correctly dealing with a patient with endoscopically proven erosive esophagitis. In such a situation consultation with a gastroenterologist would be appropriate. While the cost varies from centre to centre, the total cost for consultation, endoscopy and associated hospital charges is probably under $\$ 450.00$. This cost would be borne by the health care system on behalf of only a small group of individuals with GERD, rather than by the perhaps larger numbers being investigated now by endoscopy or by radiology, or even possibly by 'treatment trials' with a proton pump inhibitor.

An important challenge for health economists would be to assess the cost-benefit of long term maintenance therapy for patients with erosive esophagitis, using high doses of $\mathrm{H}_{2}$-receptor antagonists or omeprazole, versus a surgical antireflux procedure. A one-year course of omeprazole $20 \mathrm{mg}$ daily would be approximately $\$ 850.00$, whereas the cost of an antireflux procedure would be approximately $\$ 8000.00$. Then, some of those individuals having an antireflux procedure would be treatment failures and would need to be maintained on medical therapy. Such outcome and costbenefit studies are critically important to undertake.

At this point two serious concerns were raised. First, that the discussion on the floor has become fixed on cost-effectiveness without considering what is good for the patient. Concern was expressed that this may become a major issue of patient care in the future and that if we physicians approve of this concept, the approach will be used for all patients for all diseases. This is potentially but not necessarily deleterious for individual patient care. Secondly, the idea of calling a treatment a 'therapeutic trial' was challenged, as it was suggested that one cannot have a trial without a definite diagnosis; a trial without a diagnosis is useful only to determine whether one is dealing with something trivial, which may not even be GERD. Therefore, there should be no objection to using initial therapy with lifestyle modification, over-thecounter therapy and standard doses of $\mathrm{H}_{2}$-blockers for a defined short period such as four to eight weeks. This initial therapy should exclude omeprazole, which may suppress symptoms of a more serious condition which should be investigated. It was felt that this is the view which needs to be transmitted to family physicians.

In summary, symptoms do not always equate with severity of GERD, and we need better to identify a means of establishing the correlation between suspected clinical severity, endoscopic and histological severity, and disease progression; and furthermore, we need to determine what motivates a person to consult a physician.

\section{MANAGEMENT OF GERD}

The second major theme of the Consensus Conference dealt with the therapeutic approach to GERD. Dr Prokipchuk reported on the discussion of the group dealing with the usefulness of lifestyle modification and over-the-counter therapy. Dr DaCosta reported on the discussion whether initial drug therapy should be started with prokinetics, $\mathrm{H}_{2}$ blockers or proton pump inhibitors. Dr Connon reported on maintenance therapy for patients with GERD, and Dr Dauphinee spoke to the issue of the management of complications and the role of surgery in patients with GERD.

\subsection{The role of lifestyle modification and over-the- counter therapy in the treatment of GERD}

W Paterson introduced the topic of What is the evidence that lifestyle modification and over-the-counter therapy work in the therapy of GERD? while G Thompson introduced What is the prevalence of patients in whom lifestyle modification and over-the-counter therapy alone would work? The participants included D Daly, A Johnson, D Patel, I Prokopiw, R Reynolds and N Williams. The session was summarized by $\mathrm{E}$ Prokipchuk.

On the basis of the literature reviewed by this discussion group, there was unanimous agreement that elevation of the head of the bed, weight loss, avoidance of 'irritating' foods and beverages, decreasing or stopping smoking have proven efficacy, and should constitute first-line therapy for patients with GERD. However, there are two major difficulties for this approach:

- how to get this message to the family physician?

- how to get this message to the patient?

The group suggested that more emphasis should be put on this issue in Continuing Medical Education sessions. This is important because family doctors probably spend more time with their patients on preventive medicine than do specialists, and transmission of this information would fit their practice pattern. Just as importantly, the gastroen- 


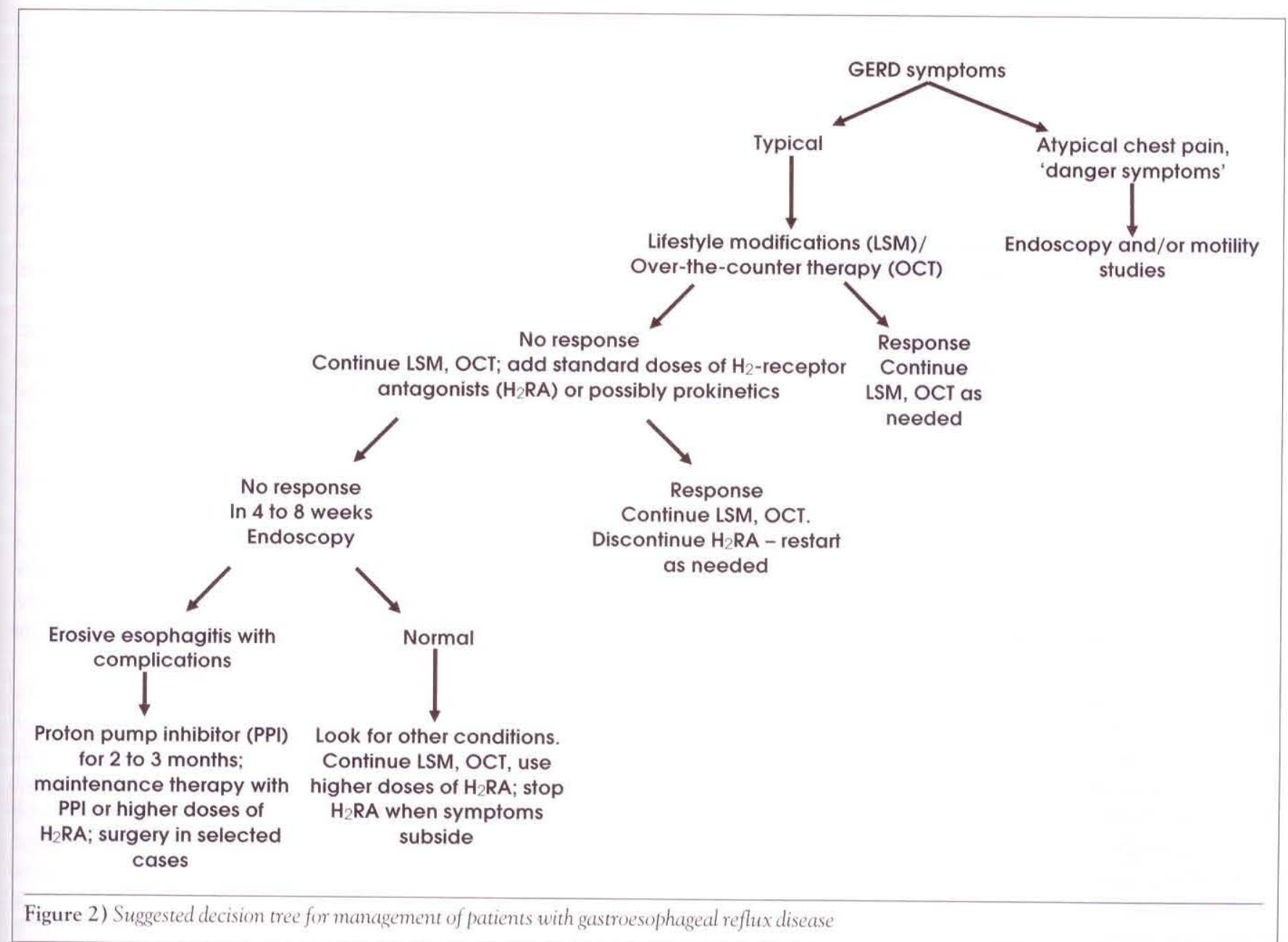

terologist should take more time to explain these measures to their patients. Rather than discussing these instructions immediately after endoscopy, when the patient's comprehension is minimal, the gastroenterologist should schedule a follow-up office visit to explain these simple management measures. The use of instruction sheets was encouraged, and it was suggested that periodic reinforcement of these lifestyle modification guidelines by family physicians and/or gastroenterologists is necessary. It was agreed that the use of antacids and alginates (over-the-counter therapies) are effective in controlling the symptoms of GERD, but all agreed that they are only adjunctive therapy.

At the plenary session Dr Johnson, one of the family physicians participating in the conference, reported on a survey he carried out on the participants. Prior to this session (during the coffee break) he had distributed a short questionnaire to all participants regarding GERD symptoms and selfmedication. It appears that half of the responding physicians had had mild GERD, and were taking antacids. Half of these were also using $\mathrm{H}_{2}$-blockers. Only one of the respondents had seen a physician for GERD. Although the findings are biased (because gastroenterologists are supposed to know what to do with symptoms of GERD), this study supports the report on the high subclinical prevalence of GERD, and the widespread use of over-the-counter therapies by persons (even physicians) who had not seen a physician.

\subsection{Should initial therapy be started with prokinetics, $\mathrm{H}_{2}$-receptor blockers or proton pump inhibitors?}

The speakers included H Chaun with Prokinetics; J Wright with $\mathrm{H}_{2}$-blockers; and L Worobetz with Proton pump inhibitors. The participants included R Bourdages, N Charland, R Clermont, JB Meddings and E Shaffer. The session was summarized by L DaCosta.

In his summary, Dr DaCosta stated that this group elected to deal with the approach to therapy according to the clinical severity of the disease. They agreed with the classic GERD triangle described by Castell (Figure 1), in which the majority of patients have only minimal and infrequent symptoms. These patients (referred to as group 1) rarely consult physicians, and self-treat with over-the-counter therapies. Patients with more troublesome symptoms (group 2) usually see their family physician. This is their first encounter with a physician regarding GERD symptoms, and in many of these patients lifestyle modifications alone are effective, and this should be the first-line of treatment. Many patients are already self-medicating with antacids, and many family physicians still use these agents widely (Figure 2). 
If a patient does not respond to lifestyle modifications and over-the-counter therapy, a trial of an $\mathrm{H}_{2}$-receptor antagonist is indicated based on the comparative safety, efficacy and cost of the three available classes of agents: prokinetics, $\mathrm{H}_{2}$-receptor antagonists and proton pump inhibitors. $\mathrm{H}_{2}$ receptor antagonists have demonstrated safety during the past 15 years. Prokinetics are also safe. Proton pump inhibitors are safe during short term therapy and probably will turn out to be safe for long term maintenance therapy. However, the group felt that we do not yet have the full story on the safety of long term therapy. This information and confidence will continue to grow with time.

$\mathrm{H}_{2}$-receptor antagonists provide symptomatic relief in about $60 \%$ of GERD patients, and healing occurs in about 30 to $40 \%$ of patients with endoscopic evidence of esophagitis. It was suggested that four to eight weeks of therapy with $\mathrm{H}_{2}$-antagonists should be adequate as initial therapy. If complete symptom relief does not occur in this period of time, either the diagnosis of GERD may be wrong, or more severe esophagitis may be present. Thus patients who are resistant to four to eight weeks of initial therapy with $\mathrm{H}_{2}$-receptor antagonists merit referral for an endoscopy.

If on endoscopy, other conditions are excluded and severe esophagitis is found, the patients should be switched to a proton pump inhibitor such as omeprazole. The literature is controversial regarding healing rates of erosive esophagitis and the most appropriate dose of omeprazole to use. Several trials suggest that there is an increase in efficacy from 20 to 40 to $60 \mathrm{mg}$ omeprazole, but a multicentre study from the USA indicates that $20 \mathrm{mg} /$ day is as effective as $40 \mathrm{mg}$ daily. Thus, the group suggested that treatment for erosive esophagitis should be started with a daily dose of omeprazole $20 \mathrm{mg}$. As to cost, $\mathrm{H}_{2}$-blockers are relatively inexpensive.

The first generation prokinetic agents (metoclopramide and domperidone) are also reasonably cheap, while the newest generation drug (cisapride) is still expensive. Similarly, proton pump inhibitors are more expensive than $\mathrm{H}_{2}$ receptor antagonists. The group suggested that prokinetics should only be used as initial therapy in patients who have systemic disease with a known or suspected motor disturbance, or possibly in those few patients who are much more troubled by regurgitation than by heartburn. Because so little is known about the use of prokinetics as maintenance therapy in patients with erosive esophagitis, this was not discussed.

At the plenary session controversy arose regarding the use of prokinetics. Some felt that prokinetics may be used as first-line drug in place of $\mathrm{H}_{2}$-antagonists, particularly in patients who have an associated nonulcer dyspepsia or 'gasbloat syndrome'. These patients do not necessarily have severe esophagitis, and may do well on primary therapy with prokinetics. Further discussion centred around the issue as to when patients should be referred for endoscopic investigation. Waiting lists to gastroenterologists are lengthy and nonresponding patients should be referred after four to eight weeks of unsuccessful $\mathrm{H}_{2}$-antagonist therapy. It was agreed that it is reasonable to suggest that the first-line approach in group 2 patients, who present to the family physician, should be $\mathrm{H}_{2}$-receptor antagonists and occasionally a prokinetic agent, rather than omeprazole, because these patients generally should be referred for investigation prior to treatment with a proton pump inhibitor. It was generally accepted that the proton pump inhibitor omeprazole is the drug of choice for patients with severe erosive esophagitis, and for patients with confirmed GERD symptoms who have not responded to standard therapy (lifestyle modification, over-the-counter therapy and a trial of standard doses of an $\mathrm{H}_{2}$-receptor antagonist). The role and safety and costbenefit of higher doses of $\mathrm{H}_{2}$-receptor antagonists remain to be established for the treatment of erosive esophagitis, and for maintenance therapy to reduce the risk of the development of erosive esophagitis.

It was pointed out that family physicians have to make their own decisions on the appropriate approach to the patient with GERD, and therefore the words 'no', 'never' or 'always' should not be used in these discussions and the wording 'should be' or 'should not be' would be preferable. These were useful suggestions and there was full agreement with this statement.

\subsection{Medical maintenance therapy}

$\mathrm{R}$ Hunt introduced When is maintenance therapy indicated and for how long? N Diamant introduced When is maintenance with $\mathrm{H}_{2}$-blockers and prokinetics indicated? D Leddin with When is maintenance with proton pump inhibitors indicated? and J Sidorov with What are the ethical aspects of long term maintenance therapy? The participants included C Carmichael, W Depew, H Haddad, A Klein, S Lemire, J McHattie and R Sherbaniuk. The session was summarized by Dr J Connon.

The first question that the group posed was whether there is a need for long term management, particularly long term medical maintenance. It is clear from the comments made by various speakers throughout this Consensus Conference that the recurrence rate of esophagitis following successful therapy is extremely high, and ranges from $75 \%$ to $90 \%$ in a six- to 12 -month period. Most if not all patients with recurrent erosive esophagitis will require therapy for symptom relief. The group discussed the potential effect of maintenance treatment on the development of complications such as ulceration, stricture formation or Barrett's esophagus. It is not known what proportion of patients will develop these complications. Thus, there is not enough information about the long term natural history of esophagitis to answer this question properly. Maintenance therapy would obviously be valuable in such a group if it were known to prevent complications as well as control symptoms.

What are the alternative strategies in relation to long term management? As far as medical treatment is concerned, there was agreement that the most effective drug currently available for the patient with erosive esophagitis is a proton pump inhibitor, that the starting dose should be omeprazole 20 to $40 \mathrm{mg}$ in the morning, with the majority of the group recommending a $20 \mathrm{mg}$ dose. Since there is a $90 \%$ relapse rate of esophagitis within one year following cessation of 
effective treatment, maintenance treatment for patients with erosive esophagitis will have to be long term, possibly life-long.

The question was raised whether or not it would be possible to switch such patients from omeprazole after healing to an $\mathrm{H}_{2}$-receptor antagonist for long term maintenance. However, there is evidence that the switch from omeprazole to standard doses of ranitidine resulted in an $85 \%$ relapse rate at the end of 12 months. The role of higher doses of $\mathrm{H}_{2}$ receptor antagonists for maintenance of remission needs to be determined. For the moment, it appears that once omeprazole has been started for erosive esophagitis, the only alternative is long term continuous treatment, or surgical therapy. The group did not feel that there was a need for routine follow-up endoscopy with previously demonstrated erosive esophagitis, but individual cases may require followup endoscopic assessment. Recurrence of heartburn while on maintenance therapy should be managed temporarily by increasing the dose of omeprazole from 20 to $40 \mathrm{mg}$ daily. However, if there was an inadequate response or if 'danger symptoms' were present, endoscopy should be repeated; when in doubt, repeat the endoscopy.

The need for long term management of patients with very mild esophagitis was discussed. It was felt that if symptoms recurred after the initial course of treatment had been completed (using lifestyle modification, over-the-counter therapy and standard doses of $\mathrm{H}_{2}$-receptor antagonists), long term maintenance should be considered. Such treatment could be with either an $\mathrm{H}_{2}$-blocker, a prokinetic agent or a combination of the two. The general opinion was against the use of a proton pump inhibitor for maintenance treatment in those patients with troublesome symptoms but minor degrees of endoscopic esophagitis. There may be the occasional individual with severe recurrent symptoms of GERD, but without endoscopic evidence of erosive esophagitis, who has symptoms of GERD unless treated with omeprazole. In view of the cyclical nature of reflux symptoms, the group recommended that periodic withdrawal of therapy would be useful in patients with little or no endoscopic changes, in order to determine whether the patient had entered a stage of remission. Again, follow-up endoscopy is often necessary for managing these complicated patents.

The group dealing with medical maintenance therapy also considered the relative role of surgery. Their recommendations were similar to those proposed by the discussion group which dealt with the indications for surgery, and this aspect of Dr Connon's summary will be discussed together with the report of that group which follows.

At the plenary session, the question of low dose and intermittent therapy with a proton pump inhibitor was raised. The literature indicates that the outcome of 'weekend therapy' with omeprazole was disappointing. However, low or intermittent doses of omeprazole may not suppress acid secretion sufficiently to maintain healing in patients with severe GERD. It was agreed that there was not enough information on this subject to come to a definite conclusion, and continuous once-a-morning maintenance therapy with omeprazole was generally recommended.
What is the legal responsibility of a physician who prescribes long term omeprazole therapy? The drug is currently authorized in Canada for only two months' use. It was agreed that before starting a patient on maintenance therapy, it is mandatory to tell the patient that the drug is authorized for only two months, and that it is not approved for long term therapy. After this statement, physicians should explain the experimental evidence of possible deleterious long term effects, but at the same time emphasize that the drug has been used now for over seven years without obvious long term toxicity. The question was also raised whether the physician contravenes the law when prescribing long term therapy with omeprazole, and therefore in case of a toxic effect the patient may have a legal right to sue the prescribing physician. A response to this concern was given by Dr Agnes Klein, one of the participants; she is Chief of the GEHO Division, Bureau of Human Prescription Drugs, Health Protection Branch, Health and Welfare Canada. Dr Klein believes that physicians are not contravening the law when prescribing long term omeprazole therapy. The legal aspect of restricting advertising and promoting a drug outside its approved limits is directed towards the manufacturer. This restriction has nothing to do with the practice of medicine. However, Dr Klein recommended that if there is concern about this issue, the question should be addressed to the Canadian Medical Protective Association.

\subsection{Medical versus surgical therapy and treatment of complications}

The topic of Medical therapy of complications was introduced by N Williams, while the topic of Indications for surgery and operations was introduced by D Mercer. The participants included T Lay, D MacNaughton and RH Ridden. The session was summarized by D Dauphinee.

One of the first questions which the group raised was: in light of the success of omeprazole, does the notion of 'refractory esophagitis' still exist? On the basis that a certain number of cases are resistant in their response to even high doses of omeprazole, and that symptomatic relapse occurs once treatment with omeprazole is stopped, the group concluded that esophagitis refractory to medical treatment probably still does rarely exist. This lead to the notion of the 'lifetime therapy' issue. Like the previous group which discussed medical maintenance therapy, this group also felt that lifetime maintenance therapy should be a physician and a patient joint decision. Thus, it was felt that the physician must discuss in detail with the patient both medical and surgical options of maintenance therapy. The alternatives must be presented fairly, appreciating that with surgical therapy there will be some loss of success with time, and that some patients may still require medical maintenance therapy. The discussion group fully supported Dr Sidorov's comments on the ethical issues of long term therapy, specifically that patients must be informed of the possible long term risks of medical or surgical therapy. One of the important issues to note is that there is evidence in the surgical literature that the 
patient who has a favorable response to omeprazole will usually have a good surgical result.

The group strongly recommended that any patient going to surgery for GERD should have esophageal $\mathrm{pH}$ monitoring and manometry performed to confirm that their symptoms are due to reflux and not to a primary motor disorder of the esophagus. Specifically, the group identified scleroderma as a disorder for which esophageal surgery was not indicated, and suggested that patients with associated esophagitis due to this condition should be managed medically. A number of other mixed connective tissue syndromes were discussed, but once the motility studies were done, the decision about surgery in these disorders could be individualized patient-by-patient.

The group then considered the management of the complications of GERD. Most acute bleeding in esophagitis is self-limiting, and may be managed by medical means. Only if bleeding is uncontrolled and cannot be stopped medically should surgery be considered. The recommended primary or initial treatment for benign stricture is dilation via the peroral route. There is no reason to pursue surgery aggressively for stricture, because by the time the patient has a stricture the results of antireflux surgery are likely to be less good than in an uncomplicated case of esophagitis.

At the plenary session it was argued that patients with long-standing strictures require life-long medical drug therapy for their esophagitis. Even if antireflux surgery is less successful in these patients, the choice between life-long drug therapy plus repeated dilations versus antireflux surgery should be discussed with the patient. Less than $5 \%$ of patients with severe esophagitis and strictures are sent for surgery by the gastroenterologists present at this meeting. Therefore, the need for individual judgement in each patient was stressed. There was no definite agreement regarding the best method of antireflux surgery.

Perforation of the esophagus (from attempted stricture dilation, or rarely arising spontaneously in patients with GERD) is usually an indication for surgery. However, medical therapy may be preferable to immediate surgery when the lesion or the infection post perforation is confined. The respiratory complications of reflux esophagitis provided the most contentious part of the group's discussion. The group agreed with the earlier comments about over-diagnosing respiratory complications from reflux disease, and that indications for surgical treatment in these situations are probably rare. If surgery is considered one certainly needs confirmation of the presence of intermittent pharyngeal acidity with $24 \mathrm{~h} \mathrm{pH}$ studies plus motility studies. The group reviewed all other complications, including extraesophageal and systemic problems such as anemia and suggested that initial treatment should be medical, assuming there is no underlying cancer.

Is the patient's age an issue in the decision to operate? The group felt that the physician's primary bias was to think of not operating on an older person, usually because of associated disease and possible co-morbidity. It was concluded that it was appropriate to manage older patients with GERD medically since this is usually a short term manage- ment situation. The group concluded that the real question relates to the decision for a younger patient and questioned whether there should there be a bias towards surgery, especially if there is a lifetime of illness and possible chronic exposure to medications. The group found this is a complex issue with a paucity of data. They recognized that the long term relapse rate of surgery for GERD in young or oldpersons is not known. Without such data, it was very hard to state the true outcome and cost of surgical therapy for GERD.

Is there endoscopic evidence that Barrett's esophagus can heal with medical management? Since there were no clear data on these issues, the group could not come to a consensus. Although there may be some histological evidence that with successful treatment in some cases areas of the metaplasia may change to squamous epithelium, the implication is not known what this means in terms of the natural history of Barrett's esophagus. The group unanimously recommended that patients with Barrett's esophagus must be treated in keeping with the recommendations made for Grade 3 or 4 ulcerative esophagitis (omeprazole), except that the patient should be monitored for dysplasia with frequent endoscopic biopsies. If the Barrett's esophagus appears to heal on endoscopy, is omeprazole stopped, and for how long? There are not enough data on the course of the disease to answer this important question.

What should be done for the patient with a massive hiatus hernia? In the absence of complications or symptoms from the hernia, the group recommended that there is probably no role for prokinetics or acid suppression. These large hernias probably start as para-esophageal hernias, and need to be monitored for possible surgical treatment should incarceration occur. However, no specific management could be recommended, and thus treatment must be individualized.

\section{CONCLUSION AND PROPOSED FURTHER AREAS OF INVESTIGATION}

On the basis of the Consensus Conference, a Decision Tree was later developed for the suggested management of patients with GERD (Figure 2 ). This reflects the approach and the recommendations brought forward in the discussion, and allows for a simple step-by-step approach to this common clinical problem. There are some hazards in accepting the opinions of any Consensus Conference as the absolute truth. First, practising physicians in the community may feel obliged to practise according to these conclusions. However, each patient may require a different approach, which should override any recommendation made here. Perhaps worse than inappropriately influencing physician behaviour is the danger that the opinions expressed at the conference may be misused by governments, hospital administrators, pharmaceutical companies and courts of law. These bodies may inappropriately consider these opinions as the only accepted approach to dealing with patients with GERD, and may try to govern the practice of physicians and render court judgements based on the opinions of this conference. It is for this reason that we would like to point out that these opinions hold only for 1992. In the future, interpretation of current 
data and knowledge may change, and as new discoveries are made, today's opinions may have lost their validity. We believe that the present conference allowed us to learn and exchange important views about GERD. The combined opinion of experts in the field of esophageal disease, tempered by the input of gastroenterologists and physicians with other varied interests and experience, provided an update and general outline for the practising physician on the classification and investigation, as well as the acute and maintenance therapy of GERD.

Throughout the conference, and in each small group discussion, the major problem in coming to conclusions was the lack of knowledge about the natural history of GERD. Does mild subclinical reflux progress to more severe GERD? Do ulcers progress to stricture? Is Barrett's esophagus, and thus cancer, the result of long-lasting ulcerative esophagitis? Decisions regarding investigation and treatment were based on the assumption that this progression does exist. This assumption was justified because of the generally accepted knowledge obtained from general pathology of other parts of the gut. Thus, it was not unreasonable for the working groups to accept that some erosions will go on to ulcers, that ulcers heal with fibrosis, that fibrosis in a narrow hollow organ may lead to stricture, that mucosal lesions may heal by metaplasia, and therefore that Barrett's esophagus is the outcome of long-lasting GERD. However, the problem is not that simple. Some patients with GERD never develop ulcers, fibrosis or Barrett's esophagus, while others present with Barrett's esophagus with minimal, or no obvious, clinical evidence of GERD. Is it possible that progression may occur in different patients at a different rate? Depending on their mucosal defence mechanisms, some patients might develop ulcers, fibrosis and Barrett's esophagus at a rapid rate while others may take much longer to progress. These hypotheses on the pathogenesis and progression of GERD must be tested in future studies. Only after a thorough understanding of the pathogenesis of GERD can we state with certainty that investigation and maintenance therapy are justified in order to prevent progression of the disease to stricture, Barrett's esophagus and cancer.

Thus, the opinions expressed here represent a consensus based on today's knowledge, and should not be taken as a definite guide to practice in every patient and under all circumstances. 


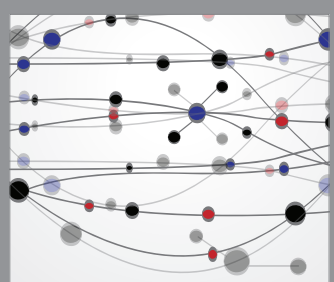

The Scientific World Journal
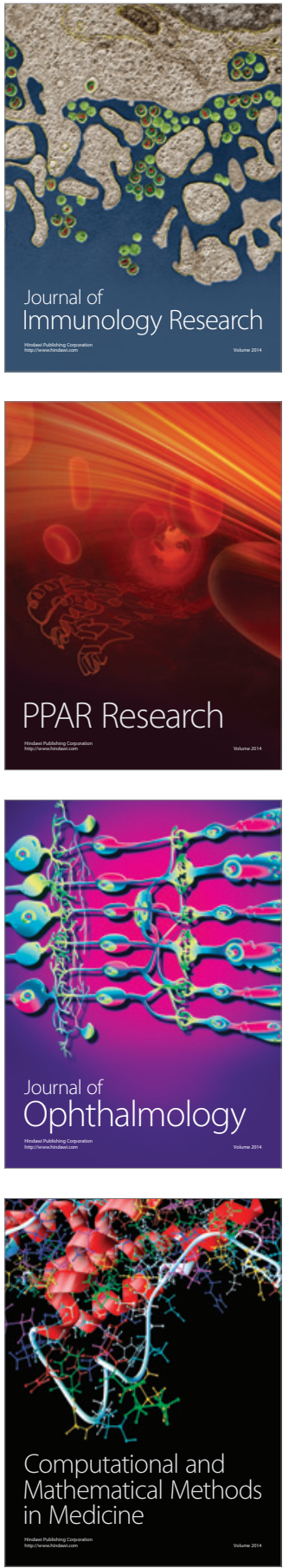

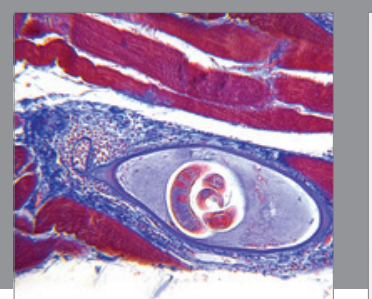

Gastroenterology Research and Practice

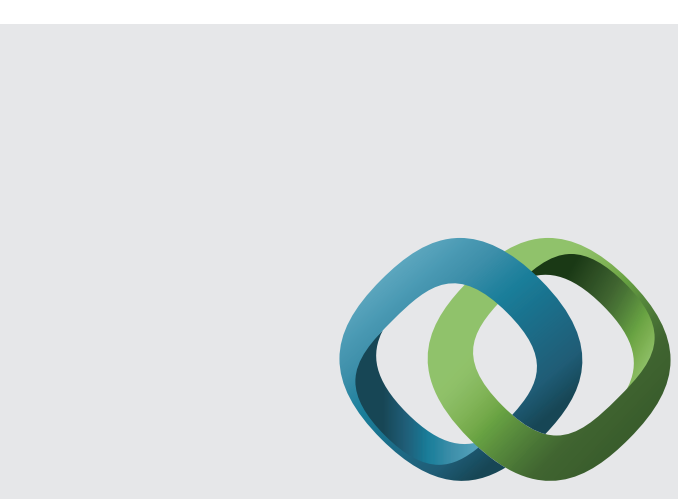

\section{Hindawi}

Submit your manuscripts at

http://www.hindawi.com
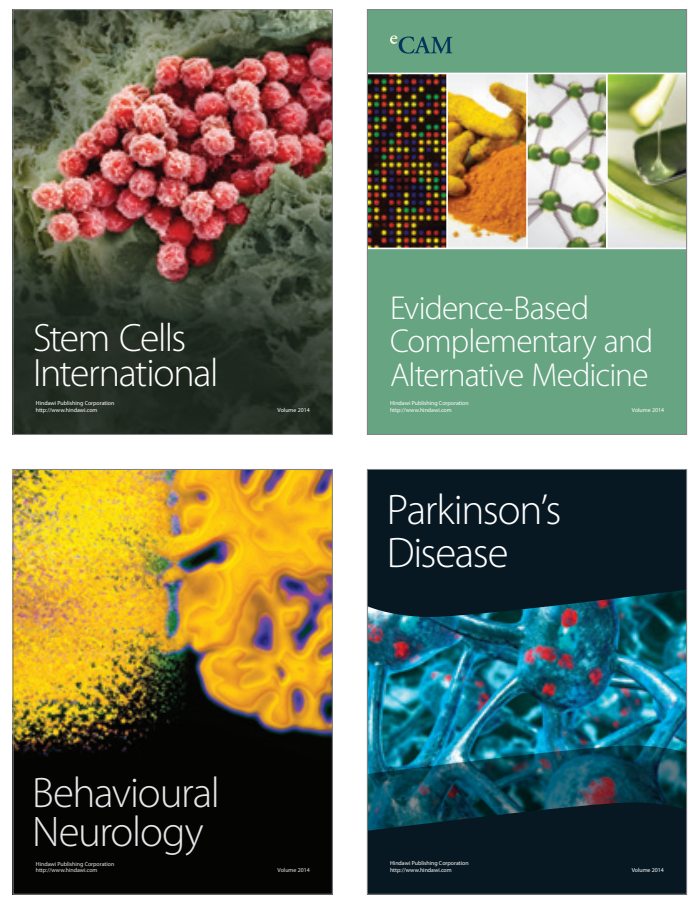
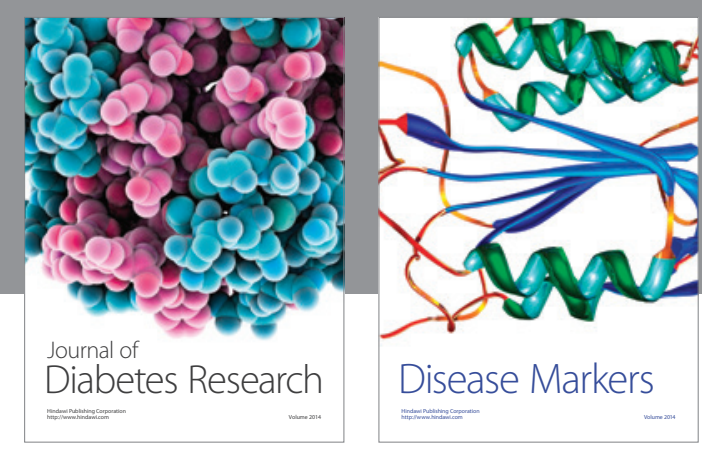

Disease Markers
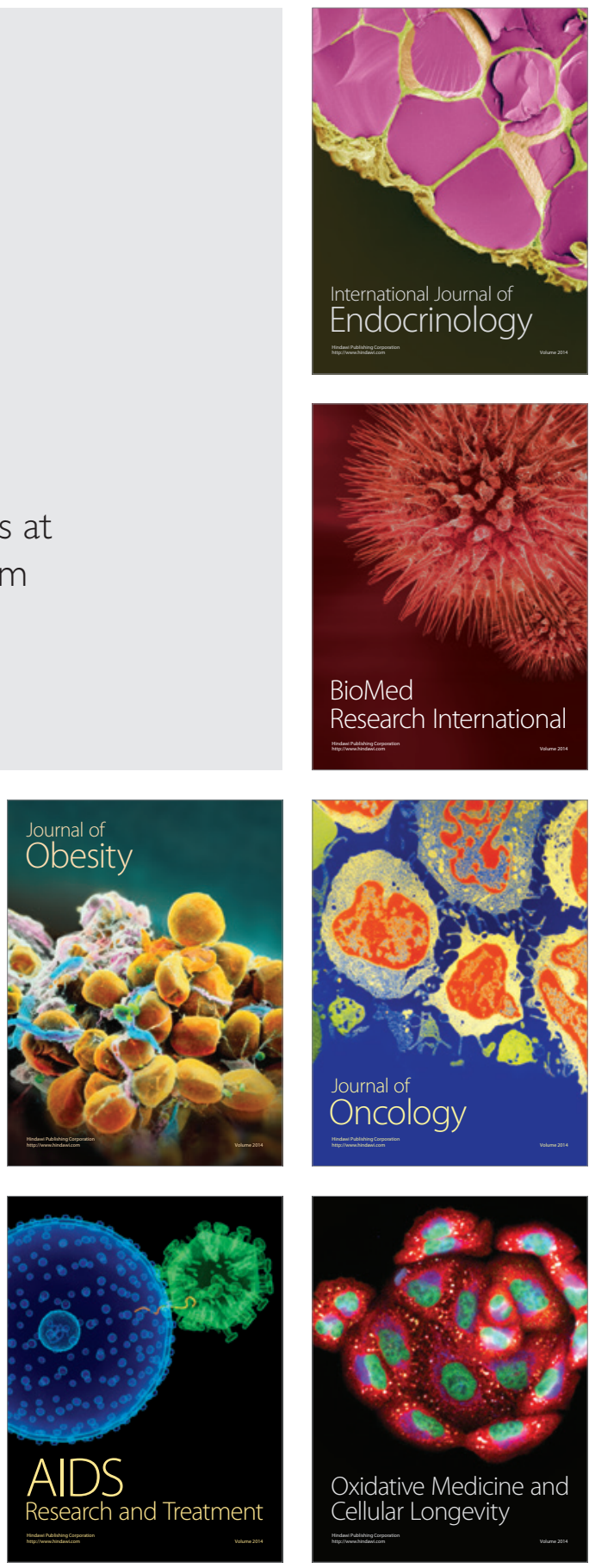